\title{
Microstructure, mechanical and functional properties of NiTi alloys processed by ECAP technique
}

\author{
E. Prokofyev ${ }^{\mathrm{a}, 1}$, D. Gunderov ${ }^{1}$, S. Prokoshkin ${ }^{2}$ and R. Valiev ${ }^{1}$ \\ ${ }^{1}$ Institute of Physics of Advanced Materials, Ufa State Aviation Technical University, 45000 Ufa, Russia \\ ${ }^{2}$ Moscow Steel and Alloys Institute, 119049 Moscow, Russia
}

\begin{abstract}
In recent years considerable attention has been focused on processing and investigation of NiTi alloys with ultrafine-grained (UFG) structure because they possess a combination of elevated mechanical and functional properties. Equal-channel angular pressing (ECAP) is the most interesting technique here as it allows avoiding pollution by impurities and obtaining bulk samples, that suitable for practical use. The aim of the given work is to systematically investigate the influence of regimes of ECAP on the microstructure, mechanical and functional properties of the NiTi alloys. It is shown that as a result of ECAP an equiaxed, homogeneous in volume, UFG structure with the grain size up to $200 \mathrm{~nm}$ is formed in the bulk rods (with the diameter 16-20 mm) of NiTi alloys. High strength (yield stress up to $1300 \mathrm{MPa}$ ) with enhanced functional properties (maximum recovery stress $\sigma_{\mathrm{r}}^{\max }$ to $1100 \mathrm{MPa}$ and maximum fully recoverable strain $\varepsilon_{\mathrm{r}}{ }^{\max }$ to $9.2 \%$ ), which is considerably higher than in the coarsegrained state is achieved.
\end{abstract}

\section{Introduction}

Owing to a unique combination of mechanical properties, shape memory effects, corrosion resistance and biocompatibility, NiTi-based alloys find progressively wider technical and medical applications as functional materials [1,2]. The problem of a further improvement in the properties of these materials is of great current interest. Substantial improvements in the various properties of bulk metals and alloys as compared to their coarse-grained analogues can be achieved by severe plastic deformation (SPD) due to the structure refinement to a nanocrystalline or ultramicrocrystalline grain size [3]. Accordingly, in recent years, much attention has become focused on the fabrication and research studies of NiTi alloys with an ultrafine-grained (UFG) structure. High pressure torsion (HPT) method was applied to produce amorphous and nanocrystalline structures in NiTi-based alloys [4-7], which allowed achieving an extraordinary strength. Equal-channel angular pressing (ECAP) technique seems to be the most important one, since it allows one to produce uniform nanostructures in bulk NiTi alloys suitable for a wide range of applications [8-9].

The purpose of this work was detailed investigate the effects of ECAP regimes on the changes of microstructure, mechanical and functional properties of a NiTi alloy.

\section{Experimental procedure}

As a material for the investigation, we selected the $\mathrm{Ni}_{50.2} \mathrm{Ti}_{49.8}$ alloy. It was produced at the Matex (Moscow) and was supplied as hot rolled rods $16 \mathrm{~mm}$ in diameter. The rods were annealed in a furnace to $800^{\circ} \mathrm{C}$ for $1 \mathrm{~h}$, and then quenched in water. The as-quenched alloy has a microstructure with an average grain size of $80 \mu \mathrm{m}$.

The UFG structure in the alloy was produced by ECAP (its detailed description is given elsewhere [3]). The variable parameters were the number of ECAP passes $(n=1,4,8$, and 12).

The microstructure and the phase composition of the deformed specimens were analyzed transmission electron microscopy (TEM). Mechanical tests at room temperature were performed on flat microspecimens with cross section of $0.25 \times 1.0 \mathrm{~mm}$ and a base length of $3 \mathrm{~mm}$ at a constant strain rate of $3 \times 10^{-4} \mathrm{~s}^{-1}$.

To characterize the functional properties of the alloy, we used the maximum recovery stress $\sigma_{r}^{\max }$ and the maximum fully recoverable strain $\varepsilon_{r}^{\max }[10]$.

a e-mail: egpro@mail.ru

This is an Open Access article distributed under the terms of the Creative Commons Attribution-Noncommercial License (http://creativecommons.org/licenses/by-nc/3.0/), which permits unrestricted use, distribution, and reproduction in any noncommercial medium, provided the original work is properly cited. 


\section{Result and discussion}

Figure 1 shows typical TEM images of the ECAP alloy structure. For all the regimes investigated, the use of ECAP dramatically, more than by a factor of 200, refines the structure elements as compared to the as-quenched state (Table 1). The structure analysis shows that ECAP results in the fact that increasing in the dislocation density and dynamic polygonization and recrystallization processes proceed in the alloy simultaneously.

The changes in the structure during ECAP and their dependence on the number of ECAP passes can be attributed, apparently, to the simultaneous occurrence of processes of deformation strengthening and relaxation. Thus, after one and four passes, a banded subgrain structure is primarily formed in the alloys. Inside the initial grains, there occur, as a rule, subgrains with low-angle boundaries, which also follows from an analysis of selected-area diffraction (SAD) patterns. The increase in the number of passes from eight to twelve leads to the preferred development of fragmentation and grain structure with an enhanced fraction of high-angle grain boundaries, which leads to a ringlike location of reflections in the SAD patterns. The grain (subgrain) size is halved as the number of passes increases from 8 to 12 (see Table 1).

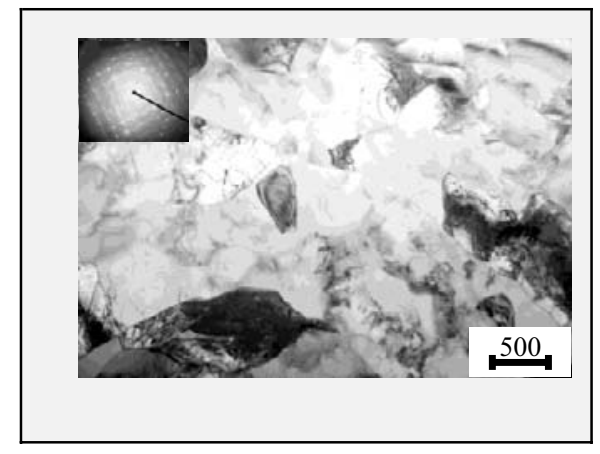

a)

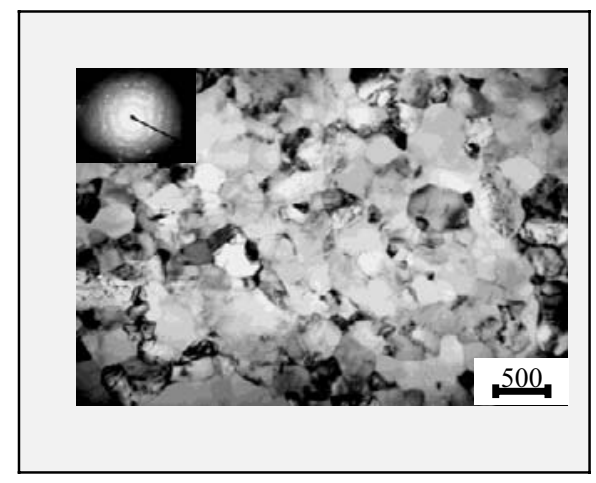

c)

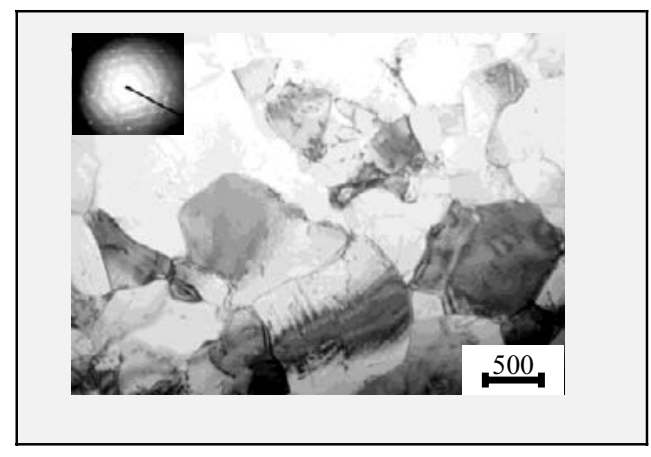

b)

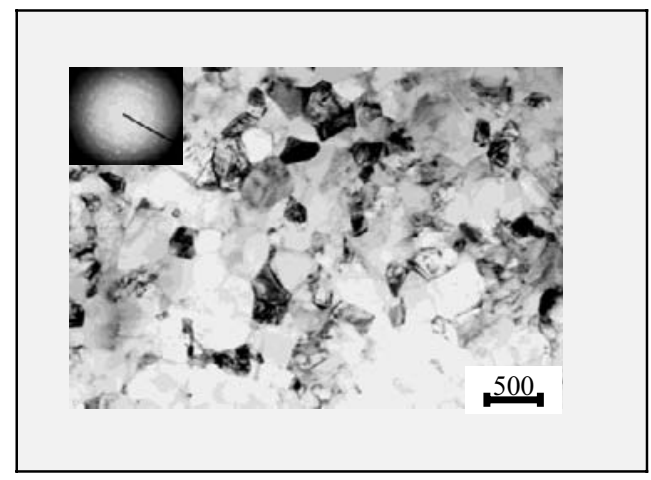

d)

Fig. 1. Microstructure of the $\mathrm{Ni}_{50.2} \mathrm{Ti}_{49.8}$ alloy after ECAP using $1(\mathrm{a}), 4(\mathrm{~b}), 8$ (c) and 12 (e) passes.

Table 1. Average grain (subgrain) size in the structure of the $\mathrm{Ni}_{50.2} \mathrm{Ti}_{49.8}$ alloy after ECAP

\begin{tabular}{|c|c|c|}
\hline \multicolumn{2}{|c|}{ State } & Grain size, $\mu \mathrm{m}$ \\
\hline \multicolumn{2}{|c|}{ Quenched, $800^{\circ} \mathrm{C}, 1 \mathrm{~h}$, water } & 80 \\
\hline \multirow{4}{*}{ ECAP } & 1 pass & 0.6 \\
\cline { 2 - 3 } & 4 passes & 0.45 \\
\cline { 2 - 3 } & 8 passes & 0.25 \\
\cline { 2 - 3 } & 12 passes & 0.25 \\
\hline
\end{tabular}

The general regularity is that the first 1-4 passes lead to a sharp refinement of the structure; then, the saturation stage occurs, at which the number of passes almost does not affect the grain (subgrain) size. Such a behavior during ECAP processes is typical of most materials [3]. 
A further increase in the number of passes (to greater than 4-8) has a more subtle influence on the structure of grains and their boundaries, namely, on the mutual orientation of grains and subgrains, the density and distribution of dislocations, and the magnitude of internal stresses.

Figure 2 shows typical tensile stress-strain curves. Table 2 lists the mechanical properties of the $\mathrm{Ni}_{50.2} \mathrm{Ti}_{49.8}$ alloy after different regimes of ECAP. As compared to the initial coarse-grained state, ECAP causes substantial changes in the stress-strain curves, leading to an increase in the coefficient of strain hardening, dislocation yield stress and strength, and the development of necking prior to failure. The last effect becomes more noticeable with increasing number of passes. Note that during tension of the coarse-grained quenched specimens, no necking in the fracture zone is usually observed.

The ultimate tensile stress (UTS) increases with increasing number of passes and reaches a maximum $(1410 \mathrm{MPa})$ after 12 passes, which is by $50 \%$ greater than in the coarse-grained material. The offset yield stress (YS) behaves analogously; moreover, its increase after 4 passes is more significant than for UTS. The largest UTS and YS increments were observed after the first four passes, while the ductility decreases only slightly in this case. The relative elongation of the alloy somewhat decreases after the first pass and then gradually decreases to $23 \%$ after 12 passes. The critical stress for the start of the martensitic transformation under tensile stress $\left(\sigma_{m}\right)$ in this alloy depends on the number of ECAP passes to a smaller degree, although also demonstrates some growth.

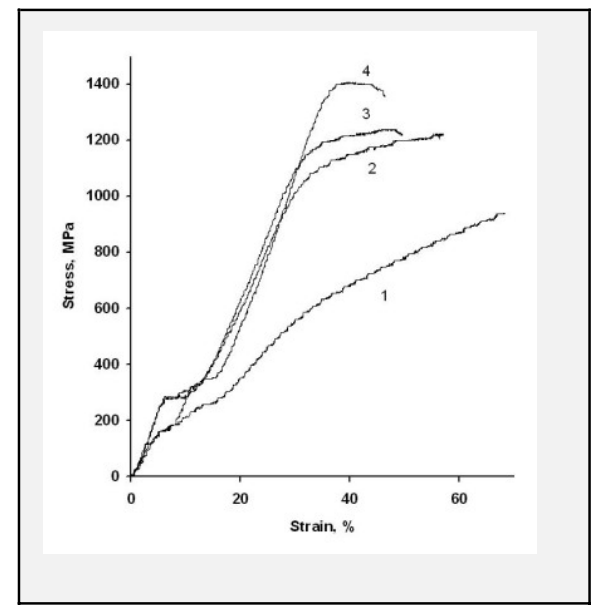

a)

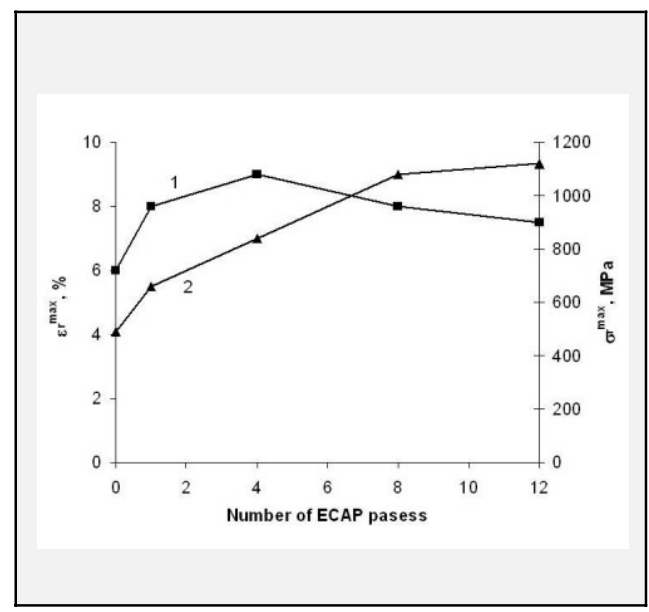

b)

Fig. 2. Engineering stress-strain curves for tensile tests (a) in coarse-grained state (1) and after ECAP using 4 (2), 8 (3) and 12 (4) passes and variation of functional properties $\left(\sigma_{\mathrm{r}}{ }^{\max }\right.$ and $\left.\varepsilon_{\mathrm{r}}{ }^{\max }\right)$ with increasing number of ECAP passes (b) of the $\mathrm{Ni}_{50.2} \mathrm{Ti}_{49.8}$ alloy

Table 2. Mechanical properties of the $\mathrm{Ni}_{50.2} \mathrm{Ti}_{49.8}$ alloy at room temperature before and after ECAP

\begin{tabular}{|c|c|c|c|c|c|}
\hline \multicolumn{2}{|c|}{ State } & $\sigma_{m}, \mathrm{MPa}$ & UTS, MPa & YS, MPa & $\delta, \%$ \\
\hline \multicolumn{2}{|c|}{ Quenched, $800^{\circ} \mathrm{C}, 1 \mathrm{~h}$, water } & 210 & 940 & 600 & 40 \\
\hline \multirow{4}{*}{ ECAP } & 1 pass & 230 & 1080 & 760 & 46 \\
\cline { 2 - 6 } & 4 passes & 290 & 1220 & 1010 & 33 \\
\cline { 2 - 6 } & 8 passes & 290 & 1240 & 1140 & 25 \\
\cline { 2 - 6 } & 12 passes & 320 & 1410 & 1360 & 23 \\
\hline
\end{tabular}

As a result of the strong structure refinement, during the first 4 passes the increase in the number of passes sharply increases UTS and the phase and dislocation YS but decreases the ductility of the ECAP alloy. Then, although the grain (subgrain) size and, apparently, the dislocation density remain almost unaffected, the strength characteristics should increase further with increasing number of passes, but at a lower rate. This evidences the preferred influence of the degree of grain misorientation with the retention of strengthening due to the size effect.

ECAP leads to a considerable increase in the maximum recovery stress $\sigma_{\mathrm{r}}{ }^{\max }$ (Fig. 2), whose value is always higher than that after quenching. The maximum effect is reached after 8-12 passes.

The change in the maximum recoverable strain $\varepsilon_{\mathrm{r}}^{\max }$ with increasing number of passes upon ECAP is displayed in Fig. 2. With increasing number of passes, $\varepsilon_{\mathrm{r}}{ }^{\max }$ first rises, namely, from $6 \%$ after quenching to $8 \%$ after one 
pass and to $9.2 \%$ after four passes. With increasing number of passes to 8 and $12, \varepsilon_{\mathrm{r}}^{\max }$ decreases slightly (to $8-$ $7.5 \%$ ), but it is still substantially higher than that of the as-quenched alloy.

The characters of changes in the functional properties of the alloy after ECAP appeared to be different. The enhancement of $\sigma_{\mathrm{r}}^{\max }$ with increasing accumulated deformation correlates with a change in the dislocation YS. Indeed, YS permanently increases with increasing number of passes of ECAP to $n=12$ (see Table 2), which is attributed to the grain (subgrain) refinement (see Table 1), increase in the fraction of grains with high-angle boundaries in the total grain (subgrain) distribution, and, accordingly, increase in the dislocation density.

The theoretical reserve of reversible deformation is determined by the crystal-lattice deformation during martensitic transformation. However, the real magnitude of $\varepsilon_{\mathrm{r}}^{\max }$ depends on the difference between the "dislocation" yield strength and "phase" yield strength (or critical stress for the martensite reorientation) $\Delta=$ YS $-\sigma_{\mathrm{m}}[1,2]$, namely, the greater the magnitude of $\Delta$, the lower the probability of the irreversible plastic deformation in the course of inducing the shape memory effect. As follows from Table 2, $\Delta$ increases permanently with increasing number of passes.

At the same time, $\varepsilon_{\mathrm{r}}^{\max }$ increases only when $\mathrm{n}$ is smaller than 4 and then slightly decreases (see Fig. 2). Apparently, the structural features induced by ECAP have an ambivalent influence on the value of $\varepsilon_{\mathrm{r}}^{\max }$. On the one hand, an increase in the dislocation density strengthens austenite and, therefore, increases $\Delta$ [11]. On the other hand, the dislocations and their pileups are obstacles (barriers) for reverse movement of the carriers of reversible deformation (grain and twin boundaries). So, apparently, there are some optimal characteristics of the dislocation substructure, namely, the density and the distribution of dislocations, such that until they are not achieved, they exert a positive influence on $\varepsilon_{\mathrm{r}}^{\max }$, whereas after they are achieved, their influence is negative. Grain refinement and grain fragmentation should increase $\Delta$. On the other hand, the grain refinement also can decrease the recoverable deformation. So, one may conclude that the final change in $\varepsilon_{\mathrm{r}}{ }^{\max }$ is a result of two opposite tendencies determining the features of the recoverable-deformation mechanism at the thermoelastic martensitic transformation in nanostructured alloys produced by SPD and specified by, on the one hand, strengthening of austenite and, on the other hand, size or barrier effect that is developed with the formation in the alloy of a ultrafine subgrain and grain structure.

Note that such a high value of the fully recoverable deformation (9.2\%) for the nearly equiatomic TiNi alloy achieved by ECAP is unprecedented and was not observed before in such TiNi alloys subjected to conventional thermomechanical treatments.

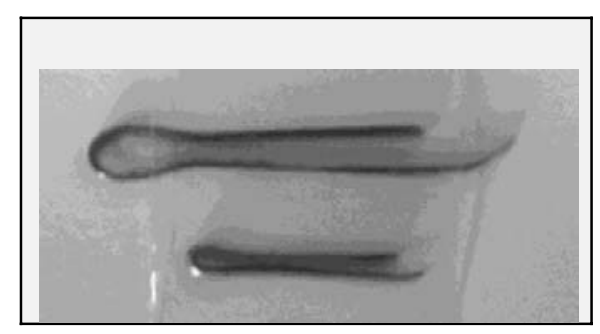

a)

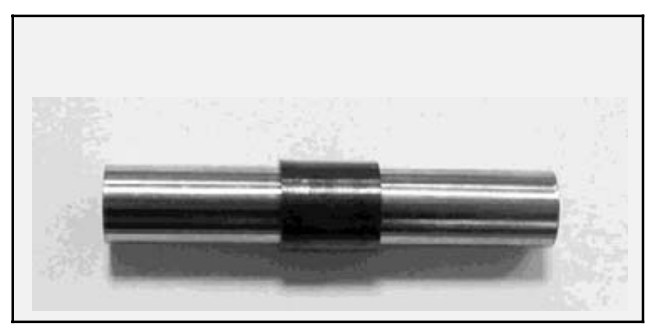

b)

Fig. 3. The examples of practical application of the UFG NiTi alloys

One of the ways of UFG NiTi practical application is the production of a clipping device for blood-vessels, tubular structures and soft tissues. This device is designed for bleeding control during laparoscopic operations (Fig. 3 a). The clip made of UFG NiTi possesses the values of reversible shape memory effect and maximum reduction force twice higher than the values of the clip produced of the conventional material. This allows making the operation less traumatic and advancing the clip's responsibility of compression and fixation structure. Another example of the UFG NiTi practical application (the alloy though contains Fe impurities) is the fabrication of a muft designed for connection of tubes and parts used in high-pressure conditions (Fig. 3 b). This muft, produced out of UFG Ni-Ti-Fe alloys, provides enhanced strength and joint leak-proofness under the influence of axial stress, rotational power and interior pressure unlike the one manufactured out of a coarsegrained alloy.

In recent years Prof. Valiev with colleagues have been developing the continuous equal channel angular pressing technique which allows producing long-length (up to $3 \mathrm{~m}$ ) semi-products with UFG or nanostructure and unique properties of many alloys including NiTi. 


\section{Conclusion}

It was established that the multipass equal-channel angular pressing (ECAP) of $\mathrm{Ni}_{50.2} \mathrm{Ti}_{49.8}$ alloy allows one to produce a uniform grain structure with predominantly highangle grain boundaries with a grain size of about 200-300 nm. ECAP increases strength and insignificantly decreases plasticity as compared to the as-quenched state. The strength increases with increasing number of passes; after ECAP using 12 passes, its increment was more than $50 \%$. The functional properties of the $\mathrm{Ni}_{50.2} \mathrm{Ti}_{49.8}$ alloy after ECAP are substantially improved. With increasing number of ECAP passes the maximum recovery stress rises to $1100 \mathrm{MPa}$ and the degree of maximum fully recoverable strain increases to $9.2 \%$.

The present work was partly supported by the Federal target program of Russian Federation government and Russian foundation for basic research.

\section{References}

[1] Shape Memory Materials. Ed. by K. Otsuka and C.M. Wayman. Cambridge: Cambridge University Press. 1999. $-284 \mathrm{p}$

[2] Shape Memory Alloys: Fundamentals, Modeling and Applications. / Ed. by: V. Brailovski, S. Prokoshkin, P. Terriault and F. Trochu. Montreal: École de technologie supérieure (ETS), Université du Québec, CANADA, 2003. $-851 \mathrm{p}$

[3] Valiev R.Z., Islamgaliev R.K., Alexandrov I.V. Progr. Mater. Sci. 2000. V. 45. 2. p. 103

[4] Pushin V.G., Stolyarov V.V., Valiev R.Z., Kourov N.I., Kuranova N.N., Prokofiev E.A., Yurchenko L.I. Annales de Chimie-Science des Materiaux. 2002. V. 27. 3. p. 77

[5] Sergueeva A.V., Song C., Valiev R.Z., Mukherjee A.K. Mater. Sci. Eng. A 2003. V. 339. p. 159

[6] Pushin V.G., Gunderov D.V., Kourov N.I., Yurchenko L.I., Prokofiev E.A., Stolyarov V.V., Zhu Y.T., Valiev R.Z. "Nanostructures and phase transformations in TiNi shape memory alloys subjected to severe plastic deformation", Ultrafine grained materials III, TMS, Charlotte: NC, USA. 2004. p. 481

[7] Waitz T., Kazyhanov V., Karnthaler H.P. Acta Mater. 2004. V. 52. 1. p. 137

[8] V.V. Stolyarov, E.A. Prokofiev, S.D. Prokoshkin, S.V. Dobatkin, I.B. Trubizina, I.Y.Khmelevskaya, V.G. Pushin, R.Z. Valiev: Phys. Met. Metallogr. 100, No. 6 (2005) p. 608

[9] Stolyarov V.V., Prokofiev E.A., Valiev R.Z., Lowe T.C., Zhu Y.T. "Structure and properties of Ti alloys processed by ECAP", Nanostructure materials by high-pressure severe plastic deformation, Proc. NATO conf. Edited by Zhu Y.T. and Varyukhin V. - 2006. - V. 212. p. 169

[10] Lin H.C., Wu S.K. Scripta Met. et Mater. 1992. V. 26, 1. p. 59

[11] Lin H.C., Wu S.K. Acta Met. et Mater. 1994. V. 42. p. 1623 